\title{
A Systematic Analysis of Research on Arcobacter: Public Health Implications from a Food-Environment Interphase Perspective
}

\author{
Chidozie Declan Iwu 1,2,*D, Temitope Cyrus Ekundayo ${ }^{1,2,3} \mathbb{D}$ and Anthony Ifeanyin Okoh ${ }^{1,2,4} \mathbb{D}$ \\ 1 SAMRC Microbial Water Quality Monitoring Centre, University of Fort Hare, Alice 5700, South Africa; \\ cyruscyrusthem@gmail.com (T.C.E.); AOkoh@ufh.ac.za (A.I.O.) \\ 2 Applied and Environmental Microbiology Research Group, Department of Biochemistry and Microbiology, \\ University of Fort Hare, Alice 5700, South Africa \\ 3 Department of Biological Sciences, University of Medical Sciences, Ondo PMB 536, Nigeria \\ 4 Department of Environmental Health Sciences, University of Sharjah, \\ Sharjah P.O. Box 27272, United Arab Emirates \\ * Correspondence: chidoziedeclan@gmail.com
}

Citation: Iwu, C.D.; Ekundayo, T.C.; Okoh, A.I. A Systematic Analysis of Research on Arcobacter: Public Health Implications from a Food-Environment Interphase Perspective. Foods 2021, 10, 1673. https://doi.org/10.3390/ foods 10071673

Academic Editors: Arun K. Bhunia and Christopher John Smith

Received: 9 May 2021

Accepted: 11 July 2021

Published: 20 July 2021

Publisher's Note: MDPI stays neutra with regard to jurisdictional claims in published maps and institutional affiliations.

Copyright: (c) 2021 by the authors. Licensee MDPI, Basel, Switzerland. This article is an open access article distributed under the terms and conditions of the Creative Commons Attribution (CC BY) license (https:// creativecommons.org/licenses/by/ $4.0 /)$

\begin{abstract}
This review maps the global research landscape of the public health implications of Arcobacter from the food-environment interphase using content analytics and integrated science mapping. The search term "Arcobacter" was used to retrieve relevant articles published in Web of Science and Scopus between 1991 to 2019. The number of articles included in the review was 524, with 1304 authors, 172 journal sources, and a collaborative index of 2.55. The annual growth rate of the publications was $9.74 \%$. The most contributing author in the field was Houf K., with 40 publications, 26 h-index, and 2020 total citations. The most productive country was the USA (13.33\%). The majority of the articles were published in English (96\%) and in the Journal of Food Protection (8.02\%). The highest research outputs were in the field of Microbiology (264). The frequently occurred keywords were Arcobacter, poultry, shellfish, cattle, and chicken. This study revealed a fair increase in the growth rate of Arcobacter-related research-especially in the area of isolation and detection of the pathogen in foods and food environments, as well as the pathogenesis and genetic diversity of the pathogen. Research themes in the area of prevalence and epidemiology seem to be underexplored.
\end{abstract}

Keywords: Arcobacter; food safety; public health; environment; gastrointestinal disease; emerging pathogen; enteric bacteria

\section{Introduction}

Arcobacter is a genus of bacteria that belongs to the Campylobacteraceae family under the Epsilonproteobacteria class [1]. They are considered non-spore-forming, spiral-shaped, motile, and fastidious Gram-negative bacteria [2]. In 1991, the genus was proposed to be a group of aerotolerant bacteria [3]. To date, the genus is made up of 27 species possessing substantial genetic diversity with increasing resistance to antibiotics [4].

Arcobacter spp. are recently regarded as emerging foodborne zoonotic pathogens affecting both humans and animals. They cause abortion and enteritis in animals and gastroenteritis, diarrhea, and bacteremia in humans [5]. Four species, including A. butzleri, $A$. cryaerophilus, $A$. thereius, and $A$. skirrowii, have been reported to be more clinically involved with human and animal infections [6]. A. butzleri has particularly been tagged as a critical threat to human health by the "International Commission on Microbiological Specifications for Foods" [7]. Human infection is usually preceded by the ingestion of contaminated raw or poorly cooked food of animal origin or contaminated water [8].

Arcobacter spp. are ubiquitous in the environment and in animals, having a vast range of hosts and habitats [4]. They have been detected in various water sources, such as sewage, lakes, rivers, and plankton [9-11], potable water [12,13], domestic and marine water [14], recreational water [15], groundwater [16], and even water delivery pipes [17]. 
Arcobacter spp. have also been found to thrive in the gut and feces of pigs [18,19], poultry meat/carcass [20,21], poultry litter [22], cattle [23], and lamb meat [24]. They have also been identified in dairy products [1,25], shellfish [26,27], and vegetables [28].

Arcobacter spp. have shown to be a very important foodborne enteric pathogen, which has captured the interest of numerous researchers worldwide. This has led to the surge in the number of published research articles regarding the pathogen and the nexus of the food environment. For instance, the prevalence of Arcobacter in food-processing facilities like poultry [29,30], diary [31-33], spinach [34], and beef [35] in countries like Denmark, Belgium, Germany, Malaysia, and Italy have been investigated and published in peer review journals. However, a bibliometric analysis that is required to measure the influence of Arcobacter-related publications in the scientific community has not been undertaken. Therefore, we carried out the first bibliometric analysis of Arcobacter-related studies between 1991 and 2019 with a specific focus on the food-environment interphase. The findings of this study will help identify the impact of published research articles regarding Arcobacter and food-environment interphase. It will also reveal those specific areas that have received increased attention by researchers, the research gaps, and provide evidence for implementing policies that will help curtail the incidence of this pathogen in the food environment, hence minimizing the public health risks posed by the pathogen.

\section{Materials and Methods}

\subsection{Sources of Arcobacter Research Data}

Research data related to Arcobacter and its public health implications from the perspective of food-environment interphase between 1991 and 2019 were retrieved from the Web of Science (WoS) and Scopus core database collections. The data were reported according to the preferred reporting items for systematic reviews and meta-analysis (PRISMA) guideline [36]. From the WoS collection, the documents were identified as 'TITLE: arcobacter*. Timespan: 1991-2019. Indexes: SCI-EXPANDED, SSCI, A\&HCI, CPCI-S, CPCI-SSH, BKCIS, BKCI-SSH, ESCI, CCR-EXPANDED, IC'. From the Scopus collection, the documents were identified as 'TITLE (arcobacter*) AND PUBYEAR $<2020$ '.

From the WoS and Scopus databases, 529 and 501 documents were retrieved, respectively, as shown in Figure 1. While 77 documents were excluded from the WoS, 54 documents were excluded from Scopus during the screening process. A total of 899 documents, therefore, met the eligibility criteria, out of which 375 documents were further excluded, due to deduplication, leaving a total number of 524 documents that were finally used in the review.

\subsection{Bibliometric Analysis of the Data}

The data of the bibliometric field were normalized and then analyzed using certain performance indicators like the trend, author rates (in terms of the number of authors, author appearances, authors of single-authored articles, authors of multi-authored articles, single-authored articles, articles/author, authors/article, co-authors/articles), growth analytics and quality metrics (conceptual domain, collaboration index, and H-index), productivity (top productive authors, top institutions, the top countries, total citations per country and top publishing journals), as well as other descriptive indices/rates related to the article, such as annual production and average citations per articles. The conceptual domain and author keywords co-word analysis was factorially mapped using the multiple correspondence analysis as described by [37].

\subsection{Analysis of the Growth Rate of Arcobacter Research}

Analysis of the growth rate of Arcobacter research concerning food, environment, microbiology, and public health was carried out. The topical growth analysis, which is based on the average growth rate (AGR) of author-keywords from 2017 to 2019, was done using Equation (1). 


$$
\mathrm{AGR}=\left(\sum_{\mathrm{i}=2017 \mathrm{sy}}^{2019 \mathrm{ey}} \mathrm{Bi}-\mathrm{Bi} \_1\right)(2019 \mathrm{ey}-2017 \mathrm{sy})+1
$$

where AGR: average growth rate., 2017 sy: start year., $2019_{\text {ey: }}$ end year., Bi: number of documents in 2017.
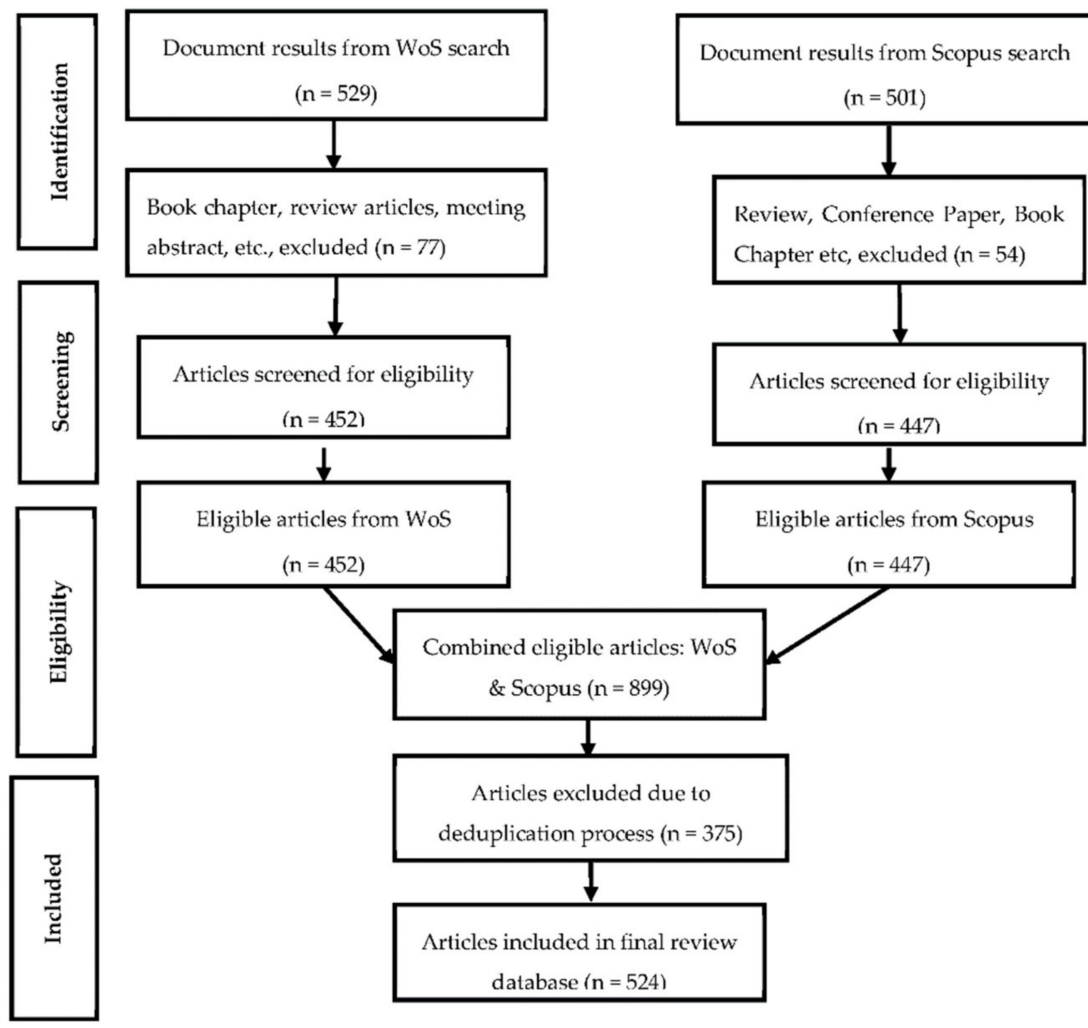

Review, Conference Paper, Book

Chapter etc, excluded $(n=54)$

Articles screened for eligibility $(\mathrm{n}=452)$
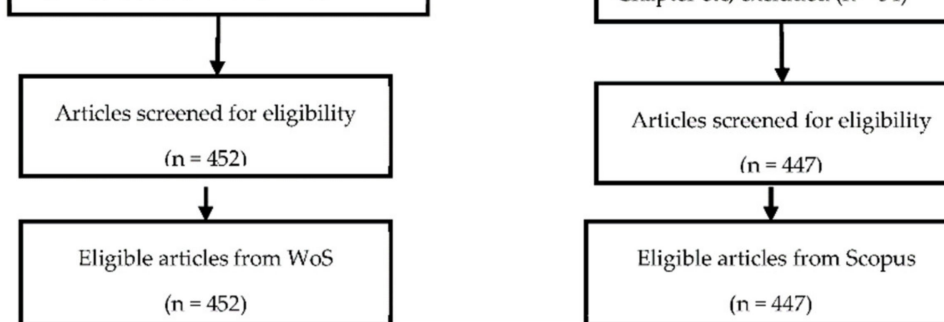

Eligible articles from Scopus

Combined eligible articles: WoS

\& Scopus $(n=899)$

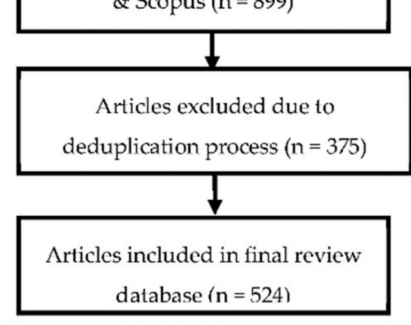

Figure 1. The PRISMA (preferred reporting items for systematic reviews and meta-analysis) flowchart of the bibliometric mapping of research related to Arcobacter and its public health implications from the perspective of food-environment interphase.

\subsection{Assessment of Arcobacter Research Scientific Networks}

Assessment of Arcobacter research scientific networks to determine scientific and intellectual collaborations were done between authors, institutions, or countries using the bipartite vectorial model below:

$$
\mathrm{Dw}=\mathrm{D} \times \mathrm{D}^{\mathrm{T}}
$$

where " $\mathrm{Dw}$ is a symmetric matrix $\left(\mathrm{D}=\mathrm{D}^{\mathrm{T}}\right)$ and composed of author collaboration network (Articles $\times$ Authors), country collaboration network (Articles $\times$ Countries), and institution collaboration network (Articles $\times$ Institutions)". D is a bipartite network matrix.

The "Fruchterman force-directed algorithms with Jaccard's similarity index normalization" [38] was used to graph the networks. The nodes/edges in the network indicate the authors, institutions, and countries, while the interconnecting lines indicate the knowledge or resource-sharing relationships. Hierarchical clustering of the authors' keywords was constructed based on Euclidean distances [39].

\subsection{Software Analysis}

Data were captured in Microsoft Excel (version 2016) and subjected to statistical analysis in $\mathrm{R}$ and python program environments using the bibliometrix $\mathrm{R}$ package [40], and the ScientoPy python package [41]. 


\section{Results and Discussion}

\subsection{The Description of the Bibliometric Data}

The information on Arcobacter-related research between 1991 and 2019 is shown in Table 1. According to the result, 524 articles from WoS and Scopus published within the date frame, involving 1304 authors, 2662 author appearances, 7 authors of single-authored documents, 1297 authors of multi-authored documents, 15 single-authored documents, and a collaborative index of 2.55 were included in the study. The study revealed 0.402 documents/author, 2.49 authors/document, 5.08 co-authors/document and a collaboration index of 2.55 with 29.23 average citations per documents. It has been shown that the quality of a study in any field is not indicated by the number of citations. Citations rather reflect the scientific impact and readership of the study to other researchers within the field [42], and this is influenced by factors, such as the visibility and accessibility of the article, as well as the year of publication.

Table 1. Main information about Arcobacter data.

\begin{tabular}{ll}
\hline Information & Counts/Rates \\
\hline Documents & 524 \\
Sources (Journals, Books, etc.) & 172 \\
Keywords Plus (ID) & 2778 \\
Authors' Keywords (DE) & 671 \\
Average citations per documents & 29.23 \\
\hline Authors & 1304 \\
Author Appearances & 2662 \\
Authors of single-authored documents & 7 \\
Authors of multi-authored documents & 1297 \\
Single-authored documents & 15 \\
\hline Documents per Author & 0.402 \\
Authors per Document & 2.49 \\
Co-Authors per Documents & 5.08 \\
Collaboration Index & 2.55 \\
\hline Document types & \\
Article & 512 \\
Article, book chapter & 9 \\
Article, proceedings paper & 3 \\
\hline
\end{tabular}

The findings of the study also indicated that the majority of the articles were published in English $(n=501,96 \%)$. Other languages identified follow the order: German $(n=6$, $1 \%)$, Spanish $(n=5,1 \%)$, Portuguese $(n=4,1 \%)$, Chinese $(n=2,1 \%)$, Dutch $(n=2,0 \%)$, English/Spanish $(\mathrm{n}=2,0 \%)$, Korea $(\mathrm{n}=1,0 \%)$ and Japanese $(\mathrm{n}=1,0 \%)$, as shown in Figure 2. Studies have shown the importance of publishing scientific findings in English. Researchers whose first language is not English are pressured to publish their scientific articles in English $[43,44]$. While some researchers prefer to use their first non-English languages, especially when the language is used globally, most researchers prefer to use English because of the desire to disseminate their findings to a wider audience, the internationalization of many Universities and research institutes, as well as many scientific journals insisting on the English language [45]. 


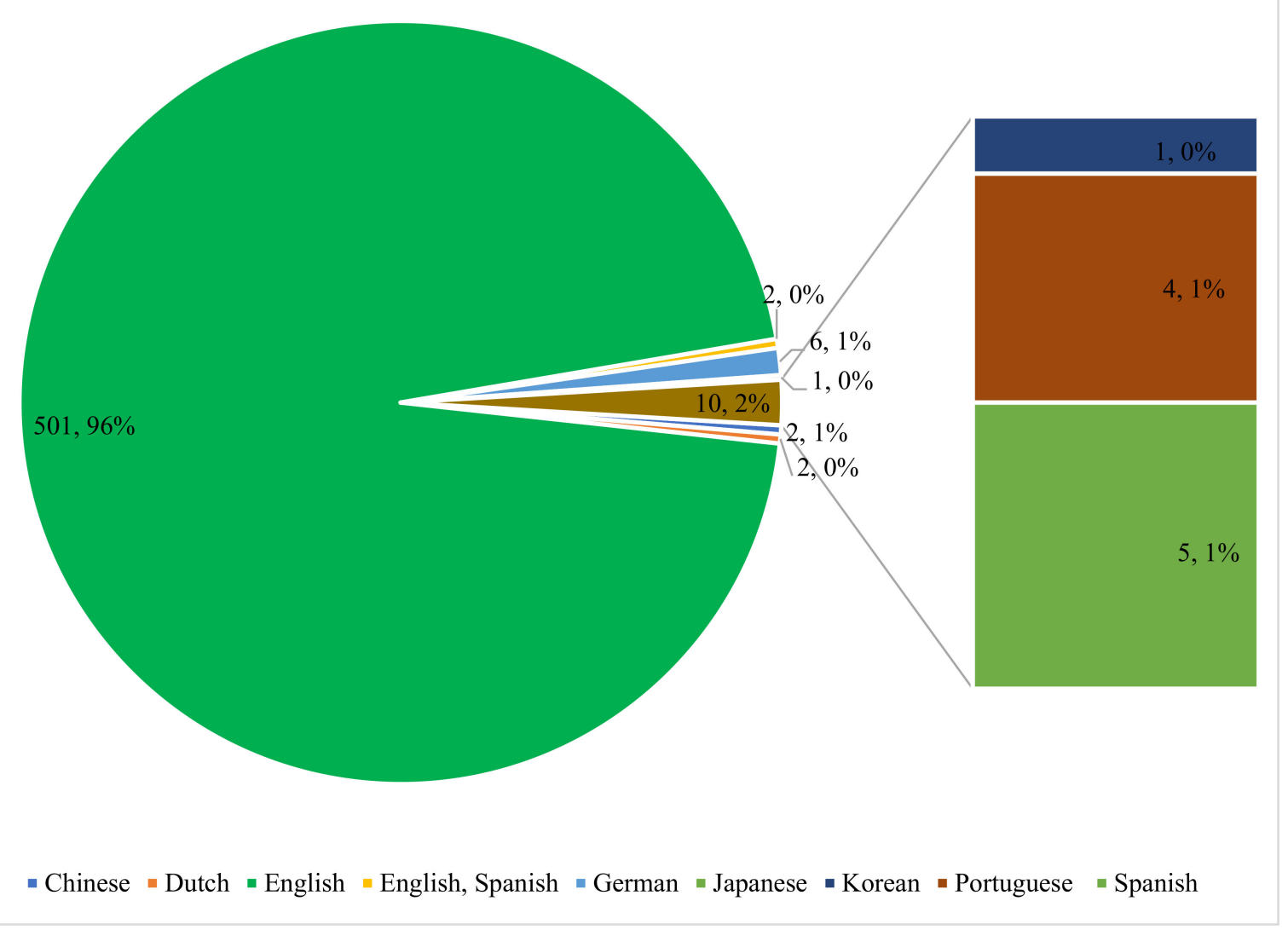

Figure 2. The language diversity of Arcobacter publications.

\subsection{Arcobacter Research Trend}

The number of publications between 1991 and 2019 follows a fairly ascending order with an annual growth rate of $9.74 \%\left(R^{2}=0.8358\right)$, as shown in Figure 3. Although, a sharp decline in the research outputs in 2005 was observed, which eventually peaked in 2007. This was followed by another sharp decline in 2009, and an increase in 2010. The highest peak of the research outputs was observed in 2013 and has remained unsteady till 2019. The fluctuations in research trends indicate that the publication of Arcobacter-related research has not been steady throughout the survey period. This is probably attributed to certain factors, such as available research funds and qualified postgraduate students who can take up Arcobacter-related research. Moreover, Arcobacter is an emerging pathogen whose evolutionary mechanisms, genetic and ecological diversity are not well understood, hence have not gained much interest from the scientific community. Despite the fluctuations, it is encouraging that there is a steady increase in Arcobacter-related research outputs, since the pathogen exhibits significant public health and food safety importance. 


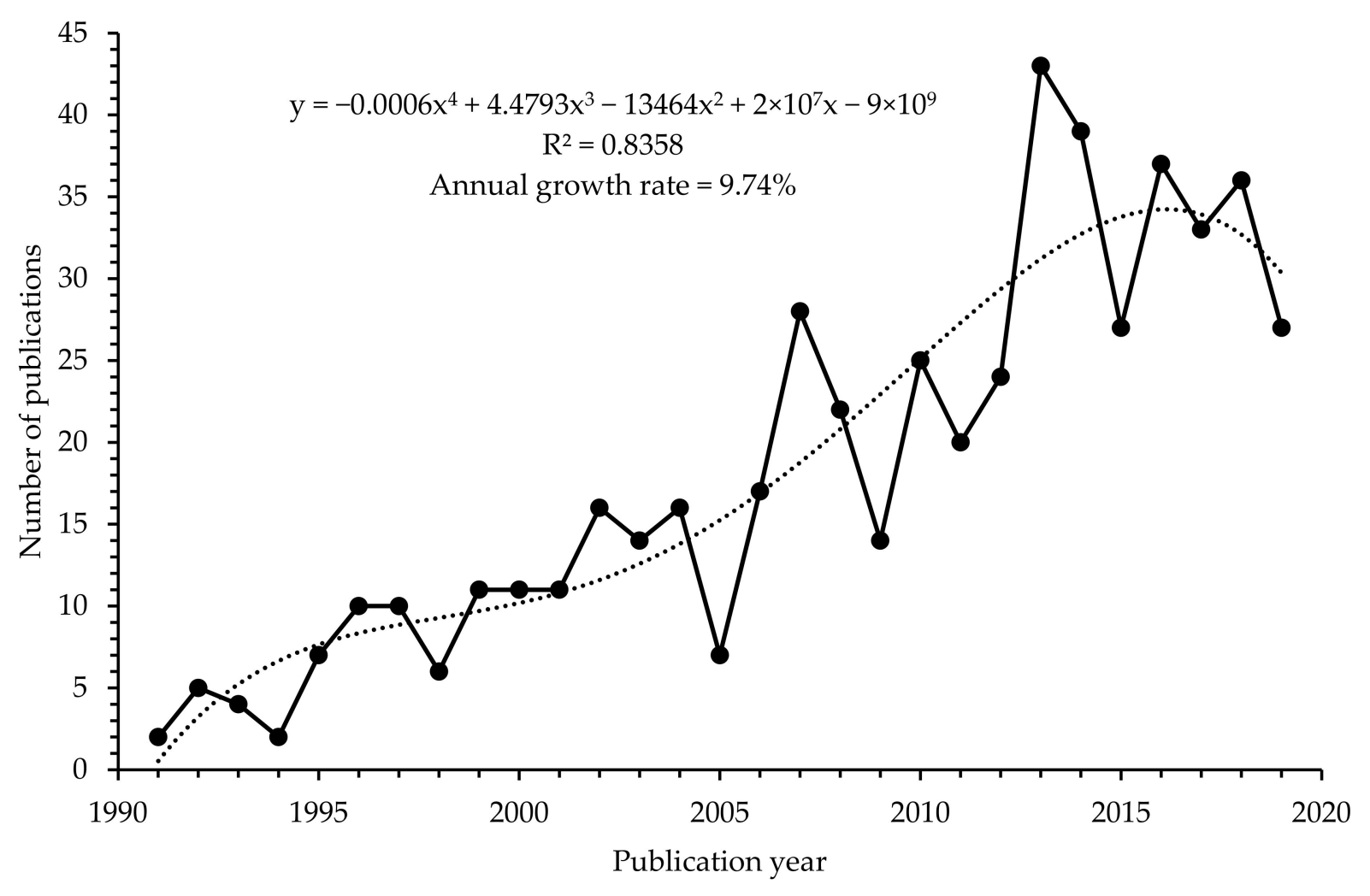

Figure 3. The number of Arcobacter publications from 1991 to 2019.

\subsection{Publication Growth}

Between 1991 to 2019, the total research outputs according to subject areas ranged from three in Gastroenterology and Hepatology., General and Internal Medicine., Parasitology., and Water Resources to 264 in Microbiology, as shown in Table 2. Also, the average growth rate (AGR) of the research outputs ranged from -0.7 in subject areas like Microbiology., Biotechnology and Applied Microbiology., and Environmental Sciences and Ecology to 1 in Food Science and Technology. Although most research outputs have been in the area of Microbiology, the subject area with the highest average growth rate is in the area of Food Science and Technology. This indicates that Arcobacter is an important emerging foodborne pathogen and is often isolated between the food-environment interphase.

The average documents per year (ADY) ranged from 0 in Chemistry., Public, Env. and Occupational Health., Toxicology., Environmental Sciences and Ecology., Research and Experimental Medicine., and General and Internal Medicine to 18.3 in Microbiology, as shown in Table 2. In the same vein, the percentage document per last three years (PDLY) ranged from 0 in Chemistry., Public, Env. and Occupational Health., Toxicology., Environmental Sciences and Ecology., Research and Experimental Medicine., and General and Internal Medicine to 33.3 in Pharmacology and Pharmacy., Gastroenterology and Hepatology., Parasitology., and Water Resources. The highest h-index was observed in subject areas like Microbiology (54)., Biotechnology and Applied Microbiology (40)., Food Science and Technology (32)., Infectious Diseases (21)., Veterinary Sciences (18)., and Immunology (12), as shown in Table 2. This indicates that the productivity and citation impact of $A r-$ cobacter-related research are within these subject areas. This is not surprising as Arcobacter represents a significant infectious disease pathogen with interesting immunological and food safety dynamics. 
Table 2. The Average Growth Rate (AGR) and Average Documents per Year (ADY) of Arcobacter research according to subject areas.

\begin{tabular}{|c|c|c|c|c|c|c|}
\hline Position & Subject & Total & AGR & ADY & PDLY & h-Index \\
\hline 1 & Microbiology & 264 & -0.7 & 18.3 & 20.8 & 54 \\
\hline 2 & Food Science and Technology & 132 & 1 & 7.3 & 16.7 & 32 \\
\hline 3 & Biotechnology and Applied Microbiology & 128 & -0.7 & 5.7 & 13.3 & 40 \\
\hline 4 & Veterinary Sciences & 51 & -1 & 3 & 17.6 & 18 \\
\hline 5 & Infectious Diseases & 32 & -0.3 & 1.7 & 15.6 & 21 \\
\hline 6 & Agriculture & 18 & -0.3 & 0.7 & 11.1 & 9 \\
\hline 7 & Immunology & 16 & 0 & 0.7 & 12.5 & 12 \\
\hline 8 & Biochemistry and Molecular Biology & 11 & -0.3 & 0.7 & 18.2 & 7 \\
\hline 9 & Science and Technology-Other Topics & 10 & -1 & 0.7 & 20 & 7 \\
\hline 10 & Pharmacology and Pharmacy & 9 & -0.3 & 1 & 33.3 & 6 \\
\hline 11 & Chemistry & 8 & 0 & 0 & 0 & 4 \\
\hline 12 & Public, Env. and Occupational Health & 6 & -0.3 & 0 & 0 & 5 \\
\hline 13 & Toxicology & 6 & 0 & 0 & 0 & 3 \\
\hline 14 & Environmental Sciences and Ecology & 5 & -0.7 & 0 & 0 & 5 \\
\hline 15 & Research and Experimental Medicine & 5 & -0.3 & 0 & 0 & 5 \\
\hline 16 & Gastroenterology and Hepatology & 3 & 0 & 0.3 & 33.3 & 2 \\
\hline 17 & General and Internal Medicine & 3 & 0 & 0 & 0 & 3 \\
\hline 18 & Parasitology & 3 & -0.3 & 0.3 & 33.3 & 3 \\
\hline 19 & Water Resources & 3 & 0 & 0.3 & 33.3 & 2 \\
\hline
\end{tabular}

PDLY: Percentage document per last three years.

The most frequently occurred keywords were Arcobacter, poultry, shellfish, cattle, and chicken, while the least occurred keywords were vegetables and rivers, as shown in Table S1. This finding is not surprising as most studies on Arcobacter have been on poultry, chicken, and pork [46]. Moreover, poultry serves as an important reservoir of Arcobacter spp. and acts as a significant source of spread [47,48]. Although some studies have identified Arcobacter spp. in water and vegetables [46], our study demonstrated that there are fewer interests within these two niches based on the generated keywords. Interestingly, the highest average growth rate of Arcobacter-related research based on the generated keywords was shellfish with an AGR of 0.7, as shown in Table S1. This indicates an increasing interest in Arcobacter-related research with a particular focus on shellfish.

\subsection{Contributing Authors and Participating Countries in Arcobacter Research}

In the present study, Houf $\mathrm{K}$. was identified as the most contributing author, with 40 publications, 26 h-index, 2020 total citations (TC), 7.7 percentage document per last three years (PDLY) of 2000. Other highly productive authors are Figueras M., Vandamme P., Wesley I., Atabay H., Miller W., Giacometti F., etc., as shown in Table 3. However, the contributing author with the highest citation was "Vandamme et al. 1991" with a total citation of 526 and a total citation per year of 18.14, as shown in Table 4. The contributing author with the least citation was "Miller et al. 2007" with a total citation of 133 and a total citation per year of 10.23. A lot of factors play a role in the citation of authors. First is the accessibility of the papers by other researchers in the field. It has been shown that papers that are published in open-access journals are more accessible to other researchers, which consequently leads to their increased citation [49]. Also, published papers in the last 10 to 15 years in open access journals tend to have more citations than those published recently. 
It has also been shown that some authors are in the habit of citing themselves [50]. This practice can cause a false citation impact on the authors.

Table 3. Most productive authors in Arcobacter research.

\begin{tabular}{|c|c|c|c|c|c|c|}
\hline Position & Authors & PUB & h-Index & TC & PDLY & PY_Start \\
\hline 1 & Houf K. & 40 & 26 & 2020 & 7.7 & 2000 \\
\hline 2 & Figueras M. & 32 & 19 & 1280 & 25 & 2008 \\
\hline 3 & Vandamme P. & 32 & 25 & 2646 & 8.7 & 1992 \\
\hline 4 & Wesley I. & 26 & 19 & 1184 & 0 & 1995 \\
\hline 5 & Atabay H. & 23 & 14 & 760 & 0 & 1997 \\
\hline 6 & Miller W. & 22 & 8 & 361 & 65 & 2007 \\
\hline 7 & Giacometti F. & 19 & 9 & 198 & 25 & 2013 \\
\hline 8 & Serraino A. & 19 & 10 & 218 & 18.8 & 2013 \\
\hline 9 & Collado L. & 18 & 16 & 1063 & 6.2 & 2008 \\
\hline 10 & De Z. L. & 18 & 15 & 1075 & 0 & 2000 \\
\hline 11 & On S. & 16 & 14 & 1041 & 15.4 & 1995 \\
\hline 12 & Alter T. & 14 & 7 & 136 & 7.1 & 2013 \\
\hline 14 & Fernndez H. & 14 & 7 & 114 & 16.7 & 1995 \\
\hline 15 & Levican A. & 14 & 13 & 590 & 0 & 2011 \\
\hline 16 & Van H. J. & 13 & 13 & 1050 & 0 & 2000 \\
\hline 17 & Yee E. & 13 & 4 & 72 & 91.7 & 2009 \\
\hline 18 & Aydin F. & 10 & 7 & 266 & 12.5 & 2001 \\
\hline 19 & Murano E. & 10 & 9 & 388 & 0 & 1996 \\
\hline
\end{tabular}

PUB: Publications, TC: Total citations, PDLY: Percentage document per last three years, PY_start: Publication start year.

Table 4. Top articles per citation.

\begin{tabular}{llccc}
\hline Rank & Author & Title & TC & TC/Year \\
\hline 1 & Vandamme et al., 1991 & $\begin{array}{c}\text { Proposal for a New Family, } \\
\text { Campylobacteraceae }\end{array}$ & 526 & 18.14 \\
\hline
\end{tabular}

Polyphasic Taxonomic Study of the Emended Genus Arcobacter with Arcobacter butzleri

2 Vandamme et al., 1992 comb. nov. and Arcobacter skirrowii sp. nov., an Aerotolerant Bacterium Isolated from Veterinary Specimens

Prevalence of Campylobacter, Arcobacter, Helicobacter, and Sutterella spp. in Human 3 Engberg et al., 2000 Fecal Samples as Estimated by a Reevaluation of Isolation Methods for Campylobacters

\begin{tabular}{|c|c|c|c|c|}
\hline 4 & Collado et al., 2011 & $\begin{array}{l}\text { Taxonomy, Epidemiology, and Clinical } \\
\text { Relevance of the Genus Arcobacter }\end{array}$ & 241 & 26.78 \\
\hline 5 & Wirsen et al., 2002 & $\begin{array}{l}\text { Characterization of an Autotrophic } \\
\text { Sulfide-Oxidizing Marine Arcobacter sp. } \\
\text { That Produces Filamentous Sulfur }\end{array}$ & 225 & 12.5 \\
\hline 6 & Houf et al., 2000 & $\begin{array}{l}\text { Development of a multiplex PCR assay for } \\
\text { the simultaneous detection and identification } \\
\text { of Arcobacter butzleri, Arcobacter cryaerophilus, } \\
\text { and Arcobacter skirrowii }\end{array}$ & 209 & 10.45 \\
\hline
\end{tabular}


Table 4. Cont.

\begin{tabular}{llccc}
\hline Rank & Author & Title & TC & TC/Year \\
\hline 7 & Vandenberg et al., 2004 & Arcobacter Species in Humans & 201 & 12.56 \\
\hline 8 & Wesley et al., 2000 & $\begin{array}{c}\text { Fecal Shedding of Campylobacter and } \\
\text { Arcobacter spp. in Dairy Cattle }\end{array}$ & 184 & 9.2 \\
9 & Vandamme et al., 1992 & $\begin{array}{c}\text { Outbreak of recurrent abdominal cramps } \\
\text { associated with Arcobacter butzleri in } \\
\text { an Italian school. }\end{array}$ & 159 \\
10 & Miller et al., 2007 & $\begin{array}{c}\text { The Complete Genome Sequence and } \\
\text { Analysis of the Epsilonproteobacterium } \\
\text { Arcobacter butzleri }\end{array}$ & 133 \\
\hline
\end{tabular}

IF: impact factor; TC: total citation, TC/Year = total citation per year.

Based on the institutional address of the corresponding authors, 36 countries were identified, as shown in Table S2. At least, 10 countries with the highest number of publications are high-income countries. The frequency of publication ranged from $0.23 \%$ in China, Mexico, Norway, Poland, Singapore, Switzerland, Thailand to $13.33 \%$ in the USA. The AGR ranged from -1.30 in Germany and Canada to 1.30 in Japan. Although Arcobacter spp. poses a global challenge, they are more reported in countries like Belgium, the United States of America, Denmark, Brazil, Australia, Italy, the Netherlands, Malaysia, Japan, Spain, Czech Republic, Korea, Egypt, and India, which are mostly high income or middle-income countries [4]. Moreover, it has been shown that high-income countries have a larger pool of trained scientific researchers, more research funding, and more equipped research facilities to isolate and characterize this emerging pathogen [51]. Interestingly, the country with the highest citation is Belgium ( $\mathrm{T}$ citation $=3737$., A citation $=86.91$ ), while the country with the least citation is Singapore ( $\mathrm{T}$ citation $=0$. , A citation $=0$ ).

\subsection{Publication Journals}

The 524 papers retrieved in this study were published across 20 most relevant journals, shown in Table S3. The five highest number of publications $(\mathrm{n}=42,8.02 \%)$ between the survey period was in the Journal of Food Protection, followed by International Journal of Food Microbiology ( $n=25,4.77 \%)$, Journal of Clinical Microbiology $(n=18,3.44 \%)$, Applied and Environmental Microbiology $(\mathrm{n}=17,3.24 \%)$ and International Journal of Systematic and Evolutionary Microbiology $(\mathrm{n}=17,3.24 \%)$. Elsevier BV/Ltd, the Netherlands, and the American Society for Microbiology, the United States were the most active publishers of Arcobacter research with three articles each. The h-index and the total citations of the journals range from 2 and 13 (Italian Journal of Food Safety) to 22 and 1265 (Journal of Food Protection), respectively. The majority of the journals are food, microbiology, and environment-related. The rest are interdisciplinary and have a common scope like tracking or detection of foodborne borne pathogens from food products or the environment.

\subsection{Collaborations Done in Arcobacter Related Research}

Resource- and intellectual sharing forms the basis for scientific networking and collaborations. The country's collaboration map indicates only four collaboration networks among all the countries involved in Arcobacter-related research, as shown in Figure 4. The first network was between Germany, the USA, Spain, and the Netherlands., the second network was between Japan, United Kingdom, and Turkey, the third network was between Italy, Belgium, and Canada., and the fourth network was between Chile and Costa Rica. Interestingly, these collaborations were basically between first-world countries. It has been shown that collaborations between developing and developed countries are rare in several scientific areas [52]. Collaborations between developed and developing countries should be encouraged to increase the exchange of knowledge and ideas relative to each region. With easy communication channels and travel opportunities, the degree of internationalization 
and exchange of ideas is rising swiftly. This provides an opportunity for universities across the world to form global partnerships and foster relationships with other institutions in other countries.

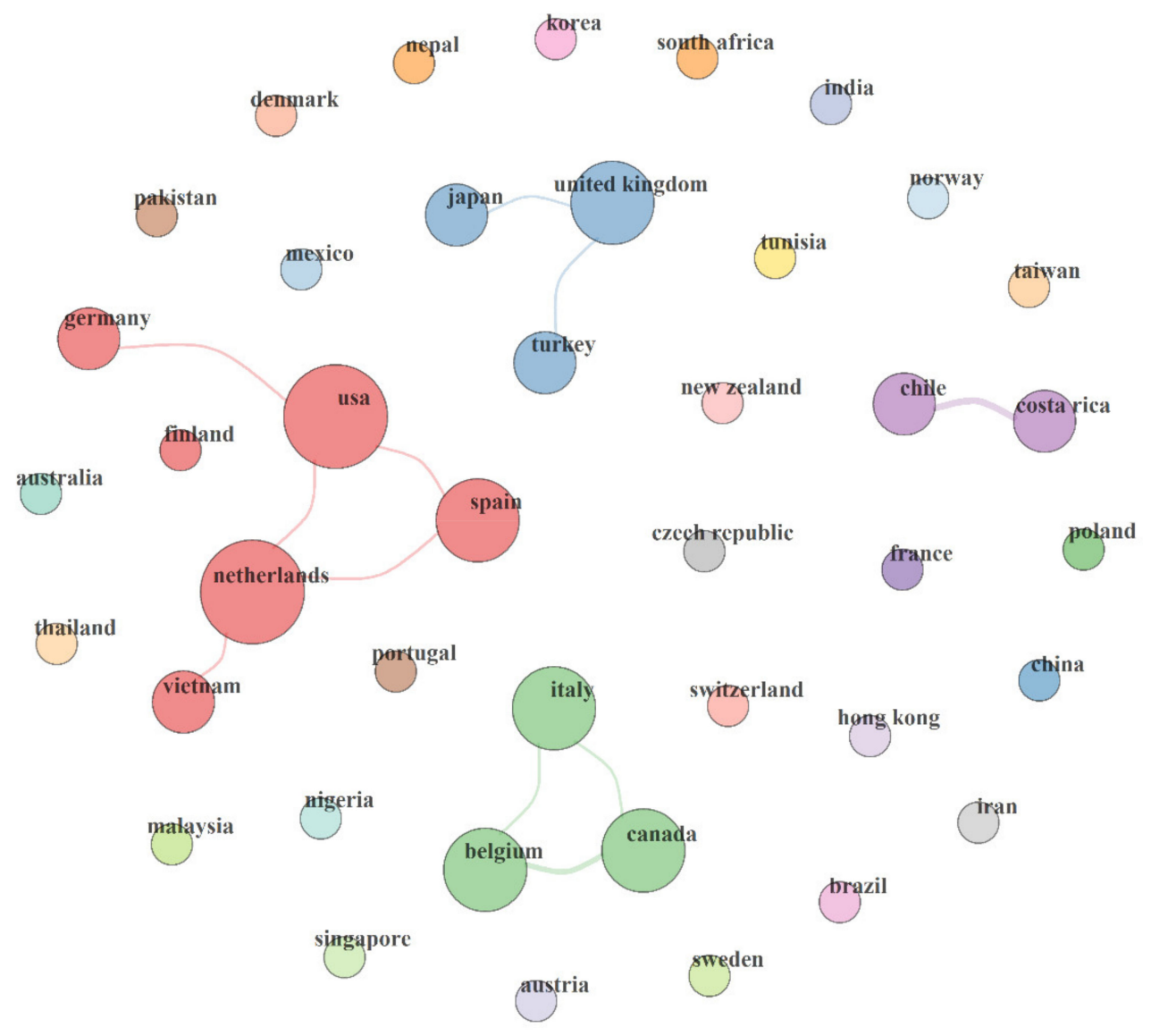

Figure 4. Country's collaboration map.

The present study identified nine institutional collaboration networks involved in Arcobacter-related research, as shown in Figure 5. These institutions vary from ministries to research institutes and Universities. Such collaborations have contributed to the progress of science. For instance, researchers from Edinburgh University collaborated with researchers from Harvard University, Peking University, Johns Hopkins University, and Nossal Institute for Global Health at Melbourne University to map out the leading causes of infant mortality in China and how it can be prevented [53,54]. Additionally, institutional partnerships provide opportunities for students and staff members to diversify their research, increase their cultural awareness and have international experiences [53]. 


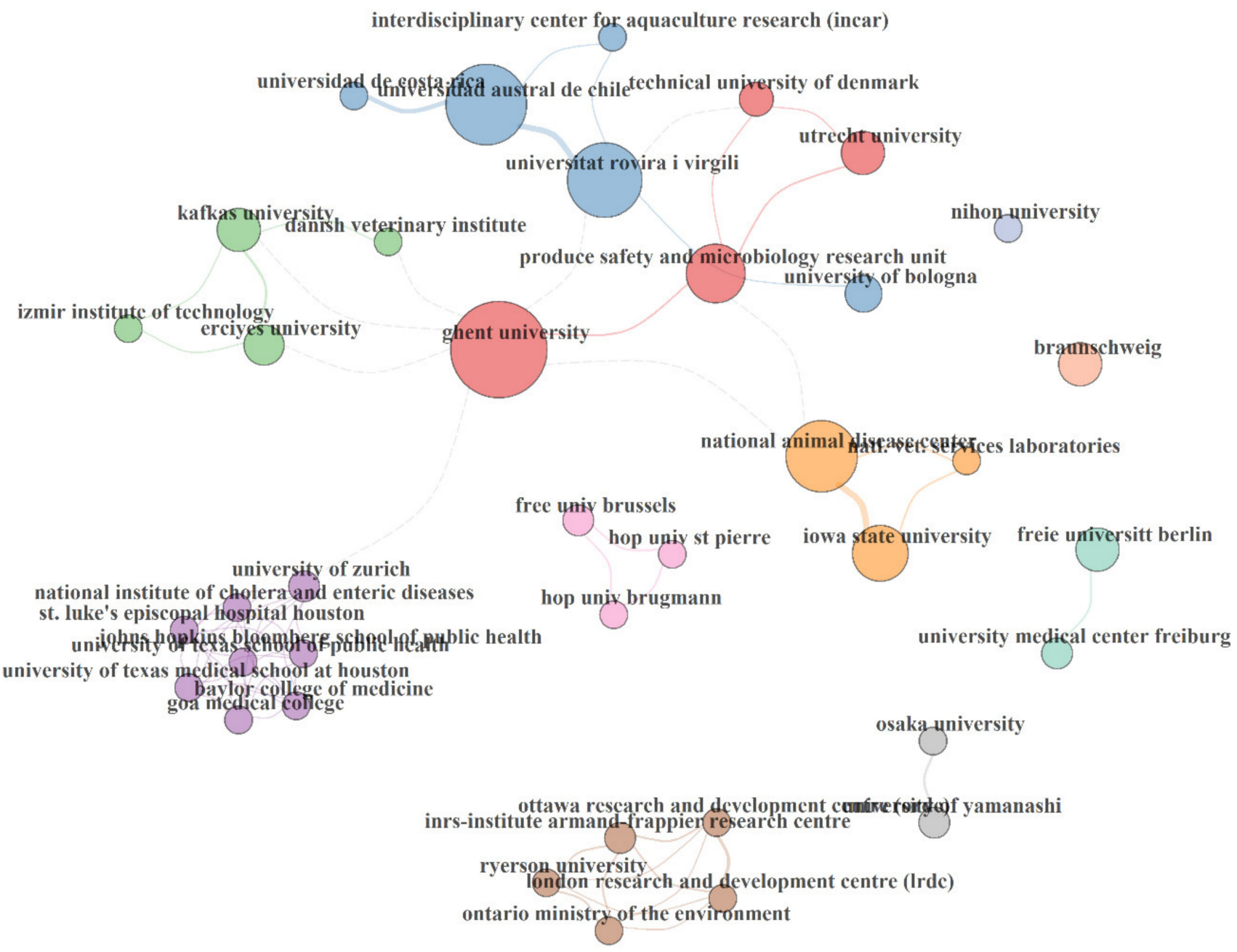

Figure 5. Institutions' collaboration map.

The keywords co-occurrence collaboration map depicts the hotspots and maps the trends of Arcobacter-related research, while the authors' keyword clusters groups the keywords that have a high correlation with each other [55]. Three keyword collaboration networks (Figure 6) and three keyword clusters (Figure 7), were identified in the present study. The first network (red color) has about 10 nodes (high-frequency words) whose sizes vary depending on the frequency of occurrence of the words. They include "Arcobacter butzleri", "Arcobacter cryaerophilus", "shellfish", "virulence genes", "chicken meat", "antimicrobial resistance", "survival", "Arcobacter spp.", "16S rRNA", "chicken meat" and "Arcbacter skirrowii". Words that frequently appear together in the same source are connected by red lines. Looking at these keywords, it is indicated that hotspots of Arcobacter-related research are within these areas and are ranked first in the hierarchical clustering of authors keywords. In the same vein, the second network (blue color) has about 14 nodes whose sizes vary depending on the frequency of occurrence of the words. Words like "Arcobacter", "Arcobacter spp.", "Multiplex PCR", "poultry", "PCR", "prevalence" had the largest size of nodes, hence are the frequently occurred words in this network. These keywords indicate an increasing area of research interest and are ranked second in the hierarchical clustering of the authors' keywords. The third network has only two nodes (green color) whose sizes are very small, indicating a low frequency of occurrence and lack of research interest, thus ranked third in the hierarchical clustering of the authors' keywords. 
campylobacteraceae

lipooligosaccharide pro-intammatory immune responses

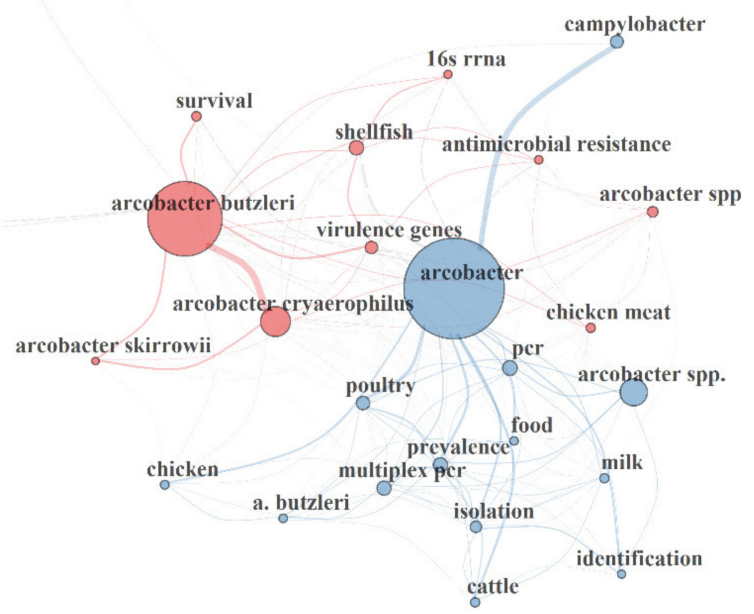

Figure 6. Keywords co-occurrence collaboration map.

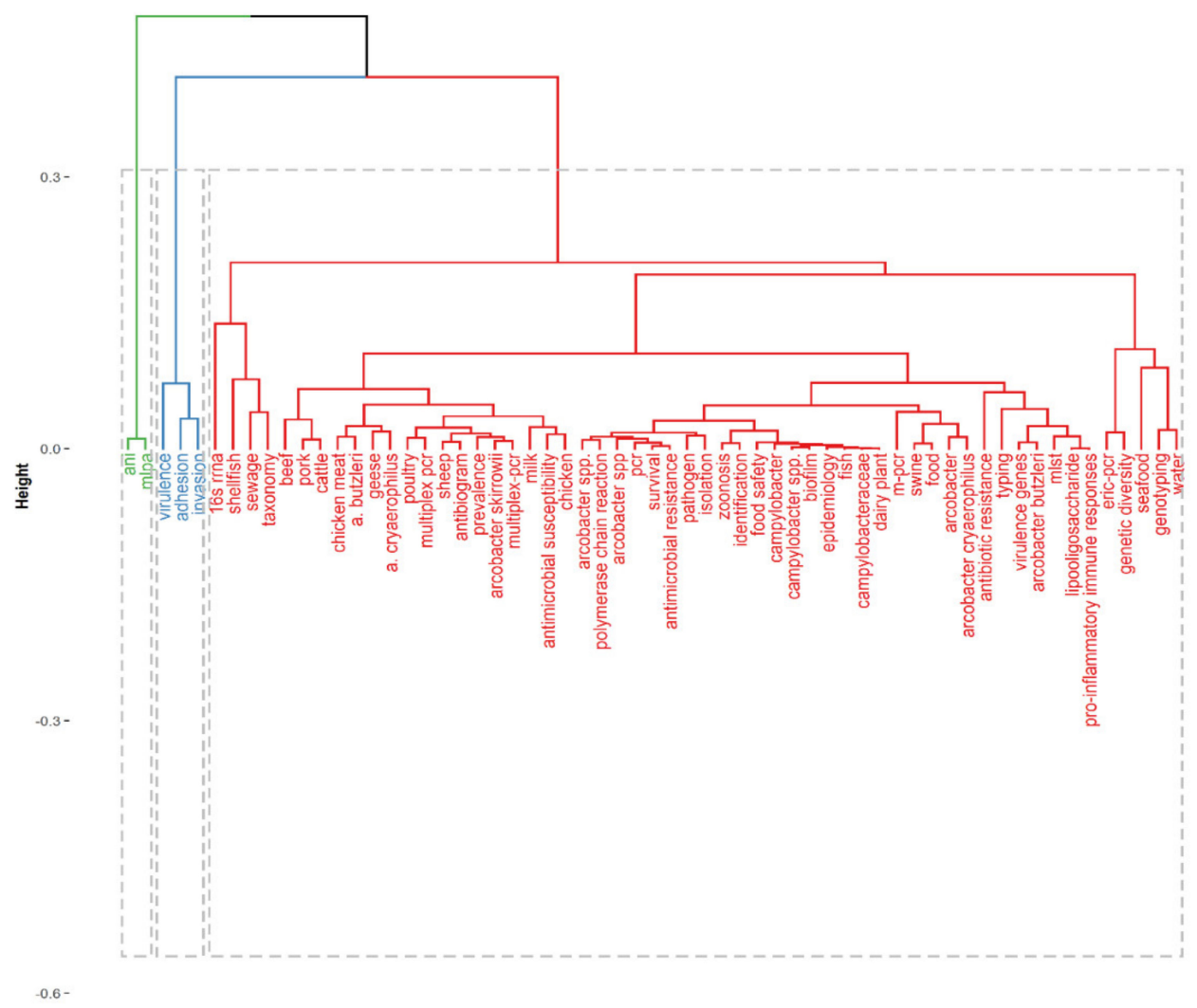

Figure 7. Hierarchical clustering of authors' keywords. 


\subsection{Conceptual Frameworks in Arcobacter Research}

A conceptual framework depicts what is expected to be found in research. In the present study, three polygons representing three major themes of Arcobacter-related research based on authors' keywords were presented in the common conceptual frames via the k-means clustering, as shown in Figure 8. Based on the generated keywords, the following themes which represents the area where Arcobacter-related research is greatly focused on include: (i) The detection and isolation of Arcobacter spp in animals, foods, and food environment using molecular methods, which are presented in the red polygon., (ii) Pathogenesis of Arcobacter spp. presented in the blue polygon., and (iii) genetic diversity of Arcobacter presented in the green polygon. Since Arcobacter spp. have been identified as an emerging foodborne pathogen with public health significance, research within these themes seems to be balanced. However, more research in the area of antimicrobial resistance and the epidemiology of the diseases caused by this pathogen should be encouraged.

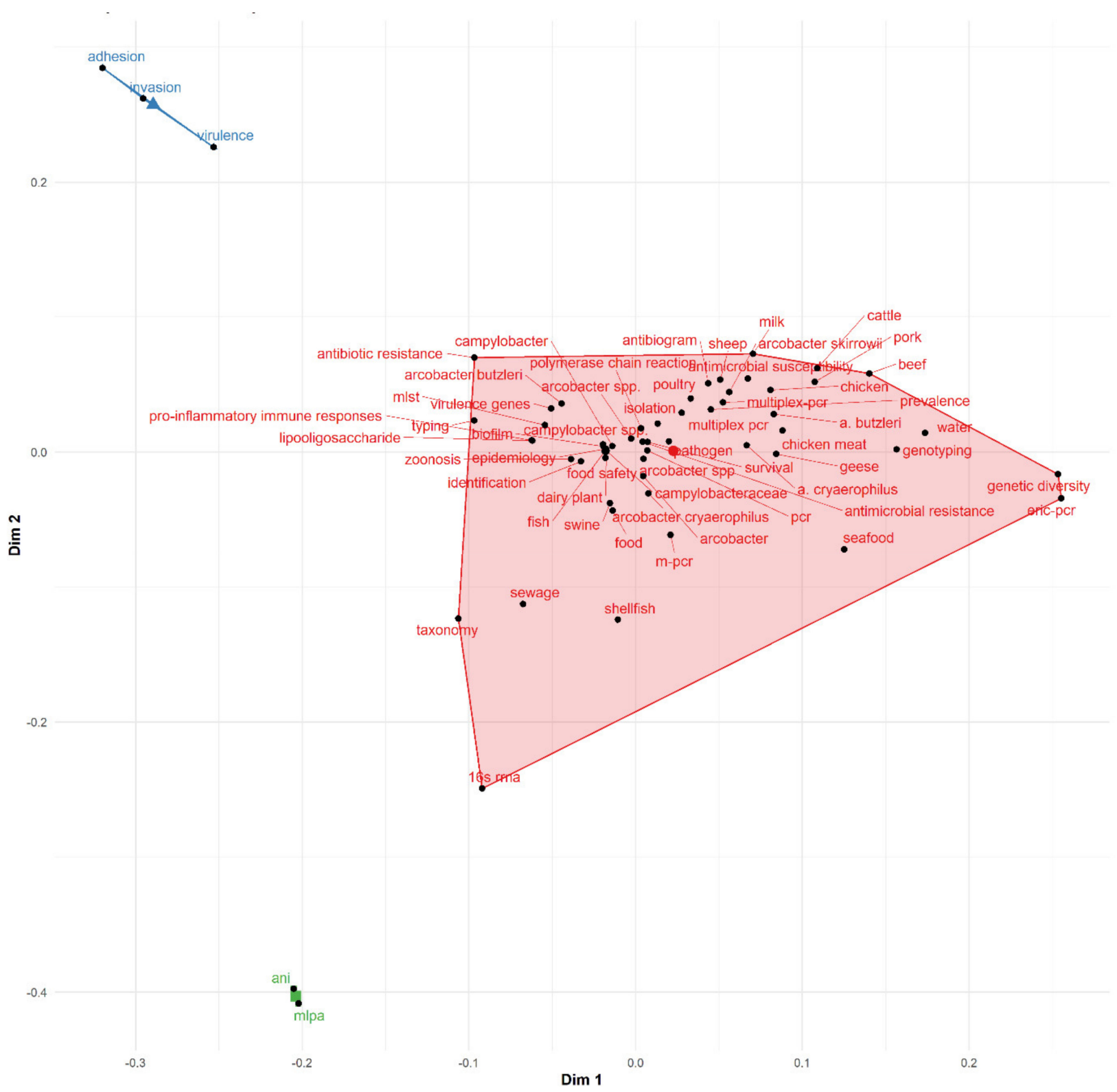

Figure 8. Conceptual frameworks in Arcobacter research. Dim 1 = Dimension 1; Dim 2 = Dimension 2. 


\subsection{Description of Studies Published in 2020}

Data on Arcobacter research outputs published in 2020 are presented in Table S4. From the WoS database, 27 journal articles written in English were retrieved. The majority of the studies were in the area of Biotechnology and Applied Microbiology; Food Science and Technology. Other prominent research areas include Gastroenterology and Hepatology; Microbiology, Food Science and Technology, as well as Biochemistry and Molecular Biology; Chemistry. Other research areas include Medical Laboratory Technology; Infectious Diseases; Agriculture and Engineering; Environmental Sciences and Ecology; and Water Resources. The Applied and Environmental Microbiology journal was the most frequently occurred journal source, followed by the Journal of Food Protection and Food Microbiology. Fanelli et al., 2020 (title: Phenotype and genomic background of Arcobacter butzleri strains and taxogenomic assessment of the species) had the highest Cited Reference Count (CRC) of 139, while On et al., 2020 (title: An emended description of Arcobacter anaerophilus Sasi Jyothsna et al. 2013: genomic and phenotypic insights) had the lowest CRC of 10.

\section{Conclusions}

The bibliometric analysis on the public health implications of Arcobacter from the foodenvironment interphase between 1991 and 2019 revealed a fair growth rate of publications within the subject area. The majority of the publications were in the field of Microbiology, while the field with the highest average growth rate is Food Science and Technology. There were greater research outputs from high-income countries with little or no collaborations with authors and institutions from low- and middle-income countries. While the research focus and theme of Arcobacter-related research are in the detection, and isolation of $A r$ cobacter spp. in animals, foods, and food environment using molecular methods, as well as understanding the pathogenesis and genetic diversity of Arcobacter spp., areas, such as the epidemiology of this pathogen is underexplored.

\section{Study Strength and Limitations}

This study was the first to provide a comprehensive and global overview of research trends on Arcobacter and its public health implications from the perspective of food-environment interphase. However, only studies from the WoS and Scopus databases were considered, thus excluding articles from other databases. Also, articles written in a language other than English were excluded. Furthermore, the quality of studies included in the studies was not assessed.

Supplementary Materials: The following are available online at https://www.mdpi.com/article/10 .3390 / foods10071673/s1, Table S1: Growth of Arcobacter research across some selected foods, food products, food animals and environment, Table S2: Country's contribution to Arcobacter research between 1991-2019, Table S3: Most relevant sources (top 20) of studies on Arcobacter between 1991-2019, Table S4: Arcobacter research data, 2020.

Author Contributions: Conceptualization, C.D.I. and T.C.E.; methodology, C.D.I. and T.C.E.; software, T.C.E.; writing—original draft preparation, C.D.I.; writing—review and editing, C.D.I., T.C.E., A.I.O.; supervision, A.I.O.; funding acquisition, A.I.O. All authors have read and agreed to the published version of the manuscript.

Funding: This research was funded by the South African Medical Research Council and the USAID/DST (South Africa) Partnerships for Enhanced Engagement in Research (PEER) Program.

Institutional Review Board Statement: Not applicable.

Informed Consent Statement: Not applicable.

Conflicts of Interest: The authors declare no conflict of interest. 


\section{References}

1. Giacometti, F.; Lucchi, A.; Di Francesco, A.; Delogu, M.; Grilli, E.; Guarniero, I.; Stancampiano, L.; Manfreda, G.; Merialdi, G.; Serraino, A. Arcobacter butzleri, Arcobacter cryaerophilus, and Arcobacter skirrowii circulation in a dairy farm and sources of milk contamination. Appl. Environ. Microbiol. 2015, 81, 5055-5063. [CrossRef]

2. Lehner, A.; Tasara, T.; Stephan, R. Relevant aspects of Arcobacter spp. as potential foodborne pathogen. Int. J. Food Microbiol. 2005, 102, 127-135. [CrossRef] [PubMed]

3. Vandamme, P.; De Ley, J. Proposal for a New Family, Campylobacteraceae. Int. J. Syst. Bacteriol. 1991, 41, 451-455. [CrossRef]

4. Ramees, T.P.; Dhama, K.; Karthik, K.; Rathore, R.S.; Kumar, A.; Saminathan, M.; Tiwari, R.; Malik, Y.S.; Singh, R.K. Arcobacter: An emerging food-borne zoonotic pathogen, its public health concerns and advances in diagnosis and control-A comprehensive review. Vet. Q. 2017, 37, 136-161. [CrossRef]

5. Di Noto, A.M.; Sciortino, S.; Cardamone, C.; Ciravolo, C.; Napoli, C.; Alio, V.; Arculeo, P.; Oliveri, G.; Costa, A. Detection of Arcobacter spp. In food products collected from Sicilia region: A preliminary study. Ital. J. Food Saf. 2018, 7, 72-75. [CrossRef]

6. Banting, G.; Figueras Salvat, M.J. Arcobacter. In Water and Sanitation for the 21st Century: Health and Microbiological Aspects of Excreta and Wastewater Management (Global Water Pathogen Project), Part 3: Specific Excreted Pathogens: Environmental and Epidemiology Aspects-Section 2: Bacteria; Rose, J.B., Jiménez-Cisneros, B., Pruden, A., Ashbolt, N., Miller, J., Eds.; Michigan State University Press: East Lansing, MI, USA, 2017.

7. ICMSF Microorganisms in Food. Microbiological testing in food safety management. International Commission on Microbiological Specifications for Foods. In Microorganisms in Foods 7; Kluwer Academic Publishing: New York, NY, USA; Springer International Publishing: Cham, Switzerland, 2002; pp. 1-30.

8. Collado, L.; Figueras, M.J. Taxonomy, epidemiology, and clinical relevance of the genus Arcobacter. Clin. Microbiol. Rev. 2011, 24, 174-192. [CrossRef]

9. Kim, H.M.; Hwang, C.Y.; Cho, B.C. Arcobacter marinus sp. nov. Int. J. Syst. Evol. Microbiol. 2010, 60, 531-536. [CrossRef]

10. Levican, A.; Collado, L.; Figueras, M.J. Arcobacter cloacae sp. nov. and Arcobacter suis sp. nov., two new species isolated from food and sewage. Syst. Appl. Microbiol. 2013, 36, 22-27. [CrossRef]

11. Park, S.; Jung, Y.T.; Kim, S.; Yoon, J.H. Arcobacter acticola sp. nov., isolated from seawater on the East Sea in South Korea. J. Microbiol. 2016, 54, 655-659. [CrossRef] [PubMed]

12. Jalava, K.; Rintala, H.; Ollgren, J.; Maunula, L.; Gomez-Alvarez, V.; Revez, J.; Palander, M.; Antikainen, J.; Kauppinen, A.; Räsänen, P.; et al. Novel Microbiological and Spatial Statistical Methods to Improve Strength of Epidemiological Evidence in a Community-Wide Waterborne Outbreak. PLoS ONE 2014, 9, e104713. [CrossRef] [PubMed]

13. Talay, F.; Molva, C.; Atabay, H.I. Isolation and identification of Arcobacter species from environmental and drinking water samples. Folia Microbiol. 2016, 61, 479-484. [CrossRef] [PubMed]

14. Merga, J.Y.; Royden, A.; Pandey, A.K.; Williams, N.J. Arcobacter spp. isolated from untreated domestic effluent. Lett. Appl. Microbiol. 2014, 59, 122-126. [CrossRef] [PubMed]

15. Lee, C.; Agidi, S.; Marion, J.W.; Lee, J. Arcobacter in Lake Erie beach waters: An emerging gastrointestinal pathogen linked with human-associated fecal contamination. Appl. Environ. Microbiol. 2012, 78, 5511-5519. [CrossRef]

16. Fong, T.T.; Mansfield, L.S.; Wilson, D.L.; Schwab, D.J.; Molloy, S.L.; Rose, J.B. Massive microbiological groundwater contamination associated with a waterborne outbreak in Lake Erie, South Bass Island, Ohio. Environ. Health Perspect. 2007, 115, 856-864. [CrossRef] [PubMed]

17. Phillips, C.A. Arcobacters as emerging human foodborne pathogens. Food Control 2001, 12, 1-6. [CrossRef]

18. Wesley, I.V.; Baetz, A.L.; Larson, D.J. Infection of cesarean-derived colostrum-deprived 1-day-old piglets with Arcobacter butzleri, Arcobacter cryaerophilus, and Arcobacter skirrowii. Infect. Immun. 1996, 64, 2295-2299. [CrossRef] [PubMed]

19. Van Driessche, E.; Houf, K.; Vangroenweghe, F.; Nollet, N.; De Zutter, L.; Vandamme, P.; Van Hoof, J. Occurrence and strain diversity of Arcobacter species isolated from healthy Belgian pigs. Res. Microbiol. 2004, 155, 662-666. [CrossRef]

20. Corry, J.E.L.; Atabay, H.I. Poultry as a source of Campylobacter and related organisms. J. Appl. Microbiol. 2001, 90, 96S-114S. [CrossRef]

21. Houf, K.; On, S.L.W.; Coenye, T.; Mast, J.; Van Hoof, J.; Vandamme, P. Arcobacter cibarius sp. nov., isolated from broiler carcasses. Int. J. Syst. Evol. Microbiol. 2005, 55, 713-717. [CrossRef]

22. Eifert, J.; Castle, R.; Pierson, F.; Larsen, C.; Hackney, C. Comparison of sampling techniques for detection of Arcobacter butzleri from chickens. Poult. Sci. 2003, 82, 1898-1902. [CrossRef]

23. Kabeya, H.; Maruyama, S.; Morita, Y.; Kubo, M.; Yamamoto, K.; Arai, S.; Izumi, T.; Kobayashi, Y.; Katsube, Y.; Mikami, T. Distribution of Arcobacter species among livestock in Japan. Vet. Microbiol. 2003, 93, 153-158. [CrossRef]

24. Rivas, L.; Fegan, N.; Vanderlinde, P. Isolation and characterisation of Arcobacter butzleri from meat. Int. J. Food Microbiol. 2004, 91, 31-41. [CrossRef]

25. Serraino, A.; Giacometti, F.; Daminelli, P.; Losio, M.N.; Finazzi, G.; Marchetti, G.; Zambrini, A.V.; Rosmini, R. Survival of arcobacter butzleri during production and storage of artisan water Buffalo Mozzarella Cheese. Foodborne Pathog. Dis. 2013, 10, 820-824. [CrossRef]

26. Mottola, A.; Bonerba, E.; Bozzo, G.; Marchetti, P.; Celano, G.V.; Colao, V.; Terio, V.; Tantillo, G.; Figueras, M.J.; Di Pinto, A. Occurrence of emerging food-borne pathogenic Arcobacter spp. isolated from pre-cut (ready-to-eat) vegetables. Int. J. Food Microbiol. 2016, 236, 33-37. [CrossRef] 
27. Leoni, F.; Chierichetti, S.; Santarelli, S.; Talevi, G.; Masini, L.; Bartolini, C.; Rocchegiani, E.; Naceur Haouet, M.; Ottaviani, D. Occurrence of Arcobacter spp. and correlation with the bacterial indicator of faecal contamination Escherichia coli in bivalve molluscs from the Central Adriatic, Italy. Int. J. Food Microbiol. 2017, 245, 6-12. [CrossRef]

28. Mottola, A.; Bonerba, E.; Figueras, M.J.; Pérez-Cataluña, A.; Marchetti, P.; Serraino, A.; Bozzo, G.; Terio, V.; Tantillo, G.; Di Pinto, A. Occurrence of potentially pathogenic arcobacters in shellfish. Food Microbiol. 2016, 57, 23-27. [CrossRef] [PubMed]

29. Andersen, M.M.E.; Wesley, I.V.; Nestor, E.; Trampel, D.W. Prevalence of Arcobacter species in market-weight commercial turkeys. Antonie van Leeuwenhoek, Int. J. Gen. Mol. Microbiol. 2007, 92, 309-317. [CrossRef] [PubMed]

30. Rasmussen, L.H.; Kjeldgaard, J.; Christensen, J.P.; Ingmer, H. Multilocus sequence typing and biocide tolerance of Arcobacter butzleri from Danish broiler carcasses. BMC Res. Notes 2013, 6, 322. [CrossRef]

31. Giacometti, F.; Lucchi, A.; Manfreda, G.; Florio, D.; Zanoni, R.G.; Serraino, A. Occurrence and genetic diversity of Arcobacter butzleri in an artisanal dairy plant in italy. Appl. Environ. Microbiol. 2013, 79, 6665-6669. [CrossRef]

32. Serraino, A.; Florio, D.; Giacometti, F.; Piva, S.; Mion, D.; Zanoni, R.G. Presence of Campylobacter and Arcobacter species in in-line milk filters of farms authorized to produce and sell raw milk and of a water buffalo dairy farm in Italy. J. Dairy Sci. 2013, 96, 2801-2807. [CrossRef]

33. Serraino, A.; Giacometti, F. Short communication: Occurrence of Arcobacter species in industrial dairy plants. J. Dairy Sci. 2014, 97, 2061-2065. [CrossRef]

34. Hausdorf, L.; Neumann, M.; Bergmann, I.; Sobiella, K.; Mundt, K.; Fröhling, A.; Schlüter, O.; Klocke, M. Occurrence and genetic diversity of Arcobacter spp. in a spinach-processing plant and evaluation of two Arcobacter-specific quantitative PCR assays. Syst. Appl. Microbiol. 2013, 36, 235-243. [CrossRef]

35. Shah, A.H.; Saleha, A.A.; Zunita, Z.; Murugaiyah, M.; Aliyu, A.B.; Jafri, N. Prevalence, Distribution and Antibiotic Resistance of Emergent Arcobacter spp. from Clinically Healthy Cattle and Goats. Transbound. Emerg. Dis. 2013, 60, 9-16. [CrossRef]

36. Moher, D.; Liberati, A.; Tetzlaff, J.; Altman, D.G.; Altman, D.; Antes, G.; Atkins, D.; Barbour, V.; Barrowman, N.; Berlin, J.A.; et al. Preferred reporting items for systematic reviews and meta-analyses: The PRISMA statement. Ann. Intern. Med. 2009, 151, 264-269. [CrossRef]

37. Ekundayo, T.C.; Okoh, A.I. A global bibliometric analysis of Plesiomonas-related research (1990-2017). PLoS ONE 2018, 13, e0207655. [CrossRef] [PubMed]

38. Jaccard, P. Distribution of alpine flora in the basin of Dranses and in some neighboring regions. Bull. Soc. Vaud. Sci. Nat. 1901, 37, 241-272.

39. Saitou, N.; Nei, M. The neighbor-joining method: A new method for reconstructing phylogenetic trees. Mol. Biol. Evol. 1987, 4, 406-425. [CrossRef]

40. Aria, M.; Cuccurullo, C. Bibliometrix: An R-tool for comprehensive science mapping analysis. J. Informetr. 2017, 11, 959-975. [CrossRef]

41. Ruiz-Rosero, J.; Ramirez-Gonzalez, G.; Viveros-Delgado, J. Software survey: ScientoPy, a scientometric tool for topics trend analysis in scientific publications. Scientometrics 2019, 121, 1165-1188. [CrossRef]

42. Shuaib, W.; Acevedo, J.N.; Khan, M.S.; Santiago, L.J.; Gaeta, T.J. The top 100 cited articles published in emergency medicine journals. Am. J. Emerg. Med. 2015, 33, 1066-1071. [CrossRef] [PubMed]

43. Swales, J.M. Research Genres Exploration and Application; Cambridge University Press: Cambridge, UK, 2004. [CrossRef]

44. Lillis, T.; Curry, M.J. Academic Writing in a Global Context: The Politics and Practices of Publishing in English; Routledge: London, UK, 2010.

45. López-Navarro, I.; Moreno, A.I.; Burgess, S.; Sachdev, I.; Rey-Rocha, J. Why publish in English versus Spanish?: Towards a framework for the study of researchers' motivations. Rev. Esp. Doc. Cient. 2015, 38, 1-16. [CrossRef]

46. Collado, L.; Guarro, J.; Figueras, M.J. prevalence of Arcobacter in meat and shellfish. J. Food Prot. 2009, 72, 1102-1106. [CrossRef] [PubMed]

47. Hassan, A.K. Detection and Identification of Arcobacter species in Poultry in Assiut Governorate, Upper Egypt. J. Adv. Vet. Res. 2017, 7, 53-58.

48. Shange, N.; Gouws, P.; Hoffman, L.C. Campylobacter and Arcobacter species in food-producing animals: Prevalence at primary production and during slaughter. World J. Microbiol. Biotechnol. 2019, 35, 146. [CrossRef]

49. Okaiyeto, K.; Ekundayo, T.C.; Okoh, A.I. Global research trends on bioflocculant potentials in wastewater remediation from 1990 to 2019 using a bibliometric approach. Lett. Appl. Microbiol. 2020, 71, 567-579. [CrossRef] [PubMed]

50. Ekundayo, T.C.; Okoh, A.I. Systematic assessment of mycobacterium avium subspecies paratuberculosis infections from 1911-2019: A growth analysis of association with human autoimmune diseases. Microorganisms 2020, 8, 1212. [CrossRef] [PubMed]

51. Vose, P.B.; Cervellini, A. Problems of scientific research in developing countries. IAEA Bull. 1981, 25, 1-40.

52. Vanni, T.; Mesa-Frias, M.; Sanchez-Garcia, R.; Roesler, R.; Schwartsmann, G.; Goldani, M.Z.; Foss, A.M. International Scientific Collaboration in HIV and HPV: A Network Analysis. PLoS ONE 2014, 9, e93376. [CrossRef]

53. Quacquarelli Symonds Why Are International Collaborations So Important For Universities? Available online: https://www.qs. com/why-are-international-collaborations-so-important-for-universities / (accessed on 22 November 2020).

54. Rudan, I.; Chan, K.Y.; Zhang, J.S.; Theodoratou, E.; Feng, X.L.; Salomon, J.A.; Lawn, J.E.; Cousens, S.; Black, R.E.; Guo, Y.; et al. Causes of deaths in children younger than 5 years in China in 2008. Lancet 2010, 375, 1083-1089. [CrossRef]

55. Chen, X.; Chen, J.; Wu, D.; Xie, Y.; Li, J. Mapping the Research Trends by Co-word Analysis Based on Keywords from Funded Project. Procedia Comput. Sci. 2016, 91, 547-555. [CrossRef] 